\title{
Effect of Different Iterative Reconstruction Algorithms on Ultra-Low Dose CT of Inflammatory Bowel Disease in a Rabbit Model
}

\author{
Cheong-Il Shin ${ }^{1,2}$, Se Hyung Kim²,2,4 Mi Hye Yu³, Ijin Joo, ${ }^{1,2}$, Joon Koo Han ${ }^{1,2,4}$ \\ ${ }^{1}$ Department of Radiology, Seoul National University Hospital, Seoul, Korea \\ 2Department of Radiology, Seoul National University College of Medicine, Seoul, Korea \\ ${ }^{3}$ Department of Radiolgy, Konkuk University Medical Center, Seoul, Korea \\ ${ }^{4}$ Institute of Radiation Medicine, Seoul National University Medical Research Center, Seoul, Korea
}

Purpose: To evaluate the feasibility of ultra-low dose $80 \mathrm{kVp} \mathrm{CT}$ for the evaluation of inflammatory bowel disease (IBD) in a rabbit model and to investigate the effect of two different iterative reconstruction (IR) algorithms on $80 \mathrm{kVp} \mathrm{CT}$ in terms of image quality and diagnostic performance in comparison with same session conventional $120 \mathrm{kVp}$ images.

Materials and Methods: This study was approved by the Animal Care and Use Committee of our hospital. Twenty-eight New Zealand white rabbits were randomly divided into two groups: IBD group ( $\mathrm{n}=18)$ and a control group $(\mathrm{n}=10)$. To create an acute IBD model, $3 \mathrm{~mL}$ of a $5 \% \mathrm{w} / \mathrm{v}$ tri-nitrobenzene sulfonic acid solution was administered to the sigmoid colon of the rabbits. CT was performed at $80 \mathrm{kVp}$ and $120 \mathrm{kVp}$ and was reconstructed using filtered back projection (FBP), hybrid statistic-based IR, and full IR algorithms for 80 $\mathrm{kVp}$ and using FBP only for $120 \mathrm{kVp}$. Effective radiation dose, image noise, image quality, and diagnostic performance by two reviewers were recorded and compared using repeated measure analysis of variance, McNemar test, and receiver operating curve (ROC) analysis.

Results: Mean effective radiation dose of $80 \mathrm{kVp} \mathrm{CT}(0.05 \mathrm{mSv})$ was significantly lower than that $(0.285 \mathrm{mSv})$ of $120 \mathrm{kVp}$ CT. Mean image noise was highest in the $80 \mathrm{kVp}$ FBP setting (60.36) but significantly decreased with IR algorithms (47.02 with hybrid IR and 12.92 with full IR) ( $\mathrm{P}<0.0001)$. Mean overall image quality score was lowest in the $80 \mathrm{kVp}$ FBP setting (1.57 and 1.46 for reviewers 1 and 2, respectively) but significantly improved with IR algorithms (2.43 and 2.25 for hybrid IR and 4.79 and 4.93 for full IR) ( $\mathrm{P}<0.0001)$. Sensitivity and area under the curve (AUC) for differentiating a normal bowel from IBD was lowest with $80 \mathrm{kVp}$ FBP $(61.1 \%$ and 83.3\%; 0.883 and 0.967) but improved with IR algorithms (83.3\% 100\%; 0.992 1), to similar levels as the $120 \mathrm{kVp} \mathrm{FBP} \mathrm{setting} \mathrm{(100 \%} \mathrm{and} \mathrm{1).} \mathrm{Differences} \mathrm{in} \mathrm{sensitivity} \mathrm{and} \mathrm{AUC} \mathrm{between} 80 \mathrm{kVp}$ FBP and $80 \mathrm{kVp} \mathrm{IR}$ algorithms were statistically significant in reviewer 1.

Conclusions: Ultra-low dose $80 \mathrm{kVp} \mathrm{CT}$ in a rabbit IBD model is not feasible using the standard FBP algorithm.

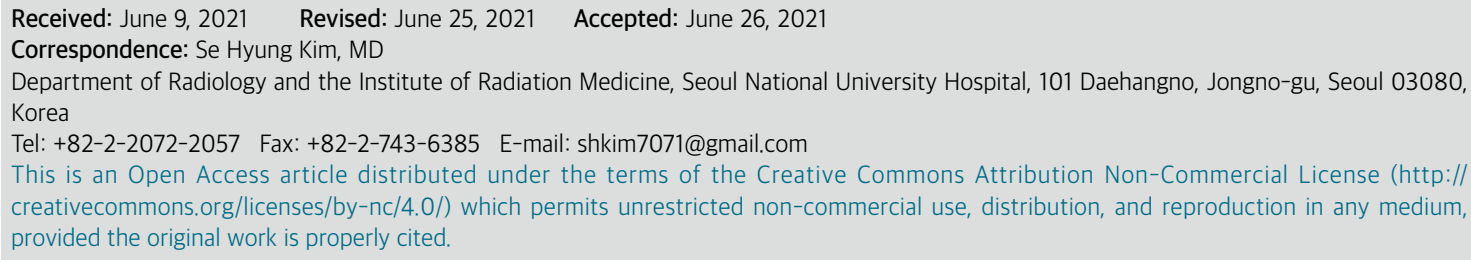


However, with the application of IR algorithms, diagnostic performance of $80 \mathrm{kVp}$ CT was acceptable and on par with that at conventional $120 \mathrm{kVp}$ FBP.

Keywords: CT; Ultra-low dose; Iterative reconstruction; Animal model; Inflammatory bowel disease

\section{Introduction}

$\mathrm{CT}$ is widely regarded as the imaging modality of choice for the evaluation of patients with known or suspected small-bowel disease $(1,2)$. Yet, despite the known utility of $\mathrm{CT}$ in assessing patients with inflammatory bowel disease (IBD), radiation exposure remains a major concern in this particular population as patients with IBD are more likely to be younger and to be imaged multiple times leading to increased cumulative radiation exposure over their lifetimes (3). Among the several dose reduction approaches used in $\mathrm{CT}$, reduction of the tube voltage from conventional $120 \mathrm{kVp}$ to $80 \mathrm{kVp}$ has been highlighted as it can potentially reduce organ dosage by up to $65 \%$ while providing the added advantage of increased iodine attenuation by a factor of 1.7 as the k-edge of iodine is closer to the reduced tube voltage $(4,5)$. However, a main limitation of low tube voltage CT for abdominal applications is the concern of image quality loss owing to increased image noise and higher susceptibility to beamhardening artifacts (6).

Recently, the development of newer image reconstruction algorithms has demonstrated the potential to overcome the increased noise that comes with low tube voltage $\mathrm{CT}$ techniques by generating images with less noise than those reconstructed with the standard filtered back projection (FBP) algorithm (7-14). Among them, adaptive statistical iterative reconstruction (ASIR) is an algorithm which repeats successive iterative transformations of the measured value of each pixel to a new estimated pixel value while comparing it to the ideal value that the noise model predicts until the final estimated and ideal pixel values converge (8-11). A more recent model-based iterative reconstruction (MBIR) product in the market, Veo, uses real 3-dimensional system optics instead of idealized system optics, directly weighing each measured projection point, thereby leading to improved overall image quality while reducing more noise than ASIR (9-11).
There has been one previous report showing the effectiveness of $80 \mathrm{kVp} \mathrm{CT}$ using these IR algorithms for small bowel diseases, however, the study was retrospectively designed and compared $80 \mathrm{kVp}$ CT with $120 \mathrm{kVp}$ CT in different patient groups (8). In addition, although both $80 \mathrm{kVp}$ CT and $120 \mathrm{kVp}$ CT were imaged in the same patient in some cases, there was a time gap between the two images in which disease activity may have been significantly different between the two CT datasets, making a direct side-by-side comparison between conventional $120 \mathrm{kVp}$ and $80 \mathrm{kVp}$ CT images impossible (8).

Therefore, the purpose of our study is to evaluate the feasibility of ultra-low dose $80 \mathrm{kVp}$ CT for the evaluation of IBD in a rabbit model and to investigate the effect of two different IR algorithms at $80 \mathrm{kVp}$ CT on image quality and diagnostic performance in comparison to same session conventional $120 \mathrm{kVp}$ images.

\section{Materials and Methods}

This study was carried out in strict accordance with the recommendations in the Guide for the Care and Use of Laboratory Animals of. The protocol was approved by the Animal Care and Use Committee of Seoul National University Hospital (Permit Number: 14-0154-S1A2). The institutional review board waived the need to obtain informed consent because this study was an animal study.

\section{Animals}

Twenty-eight male New Zealand white rabbits weighing 2.5-3.0 kg were randomly divided into two groups: 18 in the IBD group and 10 in the control group. Prior to the procedures, the rabbits were anesthetized with an intramuscular injection of a mixture of zolazepam ( $5 \mathrm{mg} /$ kg, Zoletil $®$; Virbac, Carros Cedex, France) and xylazine $(10$ mg/kg, Rompun $®$; Bayer-Schering Pharma, Berlin, Germany). 


\section{Rabbit Model of Inflammatory Bowel Disease}

After the rabbit was anesthetized, an enema was done with $100 \mathrm{ml}$ of saline to remove the feces in the rectosigmoid colon. After the enema, a Foley catheter (12 Fr, Yushin medical, Korea) was inserted via the anus placing the tip at the iliac artery bifurcation level under the guidance of ultrasonography (Accuvix XQ, Samsung Medison, Korea) using a 5-12 MHx linear probe. Ballooning was done with $2 \mathrm{~mL}$ of normal saline not to spill out the solution. To induce colitis, $3 \mathrm{~mL}$ of $5 \%$ weight/ volume 2, 4, 6 tri-nitrobenzene sulfonic acid (TNBSA) solved in methanol (Pierce Biotechnology, IL, USA) was administrated via the Foley catheter. To ensure the distribution of the TNBSA solution in the sigmoid colon, all rabbits were carefully maintained at a $30^{\circ}$ head down position for 10 minutes and then returned to their cages.

\section{CT Acquisition}

All 28 CT examinations were performed on a 64-row MDCT scanner (Discovery CT750 HD, GE Healthcare, USA). Neutral oral or rectal contrast material was not used in any of the animals. All rabbits received $6 \mathrm{~mL}$ of nonionic iodinated contrast material with an iodine concentration of $350 \mathrm{mg} / \mathrm{mL}$ (iohexol; lobrix 350, TaeJoon Pharm, Korea) followed by a $5 \mathrm{~mL}$ saline flush at a rate of $1.2 \mathrm{~mL} / \mathrm{s}$ injected with a mechanical power injector. Each rabbit was scanned at $80 \mathrm{kVp}$ first, followed by 120 $k V p$, after a default delay. The first $80 \mathrm{kVp}$ scanning was initiated in the portal venous phase 40 seconds after the administration of the contrast bolus and ranged from the dome of the diaphragm to the perineum. In all 80 and $120 \mathrm{kVp}$ examinations, the following imaging parameters were utilized: scan type, helical; gantry rotation time, 0.5 seconds; detector configuration, $0.625 \mathrm{~mm} \times 64$; pitch, 0.984; and speed, $79 \mathrm{~mm} / \mathrm{s}$. The tube currents utilized were $10 \mathrm{~mA}(5 \mathrm{mAs})$ and $20 \mathrm{~mA}(10 \mathrm{mAs})$ at $80 \mathrm{kVp}$ and $120 \mathrm{kVp}$, respectively. The FBP algorithm was used for image reconstruction of all $80 \mathrm{kVp}$ and $120 \mathrm{kVp}$ examinations and $50 \%$ ASIR and MBIR were additionally used for image reconstruction of $80 \mathrm{kVp}$ examinations. Thus, four CT datasets (80 kVp FBP, $80 \mathrm{kVp} \mathrm{50 \%} \mathrm{ASIR,} 80$ $k V p$ MBIR, $120 \mathrm{kVp} F B P$ ) for each of the 28 rabbits yielded a total of 112 image sets. All images were reconstructed with axial $1.25 \mathrm{~mm}$ slice thickness at $1.25 \mathrm{~mm}$ intervals.

\section{Effective Dose Estimation}

Scanner-generated volume CT dose index (CTDI vol ) and dose length product (DLP) were recorded for each examination. Effective dose (ED) for the examination was calculated by multiplying the DLP by a factor of 0.015 , which is the dose conversion factor for CT of the abdomen and pelvis according to the guidelines provided in Publication 60 of the International Commission on Radiological Protection (15).

\section{Quantitative Image Analysis}

Quantitative analysis was performed on picture archiving and communication system (PACS) workstations (PacsViewer, Infinitt, Seoul, Korea) using high-resolution monitors (2048x2560, Barco, Belgium). An abdominal radiologist with 11 years of experience (C.I.S.) measured image noise by recording the standard deviation (SD) of attenuation in Hounsfield units within a $0.3-\mathrm{cm}^{2}$ region of interest (ROI) placed in both the paraspinal muscles and in retroperitoneal fat at the level of the second lumbar vertebral body. All of the ROls were placed in the same location for each of the reconstructed datasets using the copy and paste function of the PACS software. The average SD of the three measurements was recorded as the image noise.

\section{Qualitative Image Analysis}

Two board-certified abdominal radiologists (S.H.K. and C.I.S. with 18 and 11 years of experience, respectively), blinded to the scan technique, independently reviewed the axial CT images on a workstation in random order. In their review, four characteristics of each examination as described below were evaluated according to a previously described method on a 5-point scale, with 1 being the lowest and 5 the best $(1=$ poor, $2=$ acceptable, $3=$ good, $4=$ very good, $5=$ excellent): The first characteristic was the adequacy of the examination for bowel imaging, in which the reviewers evaluated their ability to identify fold patterns in a distended loop bowel and to differentiate normal from abnormal bowel loops in patients with suspected bowel disease. The second characteristic was the visibility of mesenteric vessels, in which the reviewers evaluated their ability to identify vessels in the adjacent mesentery within $1 \mathrm{~cm}$ of the bowel wall. The third characteristic was the evaluation of the liver, in which the 
reviewers assessed whether there was preservation of a sharp outline of the liver and portal venous branches and assessed the level of parenchymal noise. Finally, the fourth characteristic was the overall quality of the study, in which reviewers assessed whether the examination was adequate for interpretation and whether there was image noise that might obscure pathologic findings.

\section{Evaluation for Diagnostic Performance}

To evaluate the diagnostic performance of the $80 \mathrm{kVp} \mathrm{CT}$ technique in comparison with the $120 \mathrm{kVp}$, two different abdominal radiologists (M.H.Y. and I.J. with 8 years of experience) evaluated all 112 CT examinations in random order in a separate reading session. They were blinded to the final diagnosis for the presence or absence of IBD and to which segments of the bowel were involved in cases of disease. The presence or absence of IBD was recorded on a 5-point scale: 1 , definitely normal; 2 , probably normal; 3, possibly IBD; 4, probably IBD; 5, definitely IBD. Animals with recorded grades of 3-5 were grouped as having IBD while those with grades of 1 and 2 were considered to be normal and without bowel disease.

\section{Statistical Analysis}

All statistical analyses were performed using SPSS statistical software version 21.0 (IBM, Armonk, NY, USA) and Graphad Prism version 6 (GraphPad Software, La Jolla, (A, USA). The paired t test was used to assess statistically significant differences in $\mathrm{CTDI}_{\mathrm{vol}}, \mathrm{DLP}$, and ED between the $80 \mathrm{kVp}$ and $120 \mathrm{kVp}$ settings. Image noise and subjective scores of image quality parameters of the four image datasets were compared using repeated measure analysis of variance. A p value of $<0.05$ was considered to indicate a statistically significant difference. For evaluation of the diagnostic performance in differentiating a normal bowel from IBD, sensitivity, specificity, and areas under the curve (AUCS) of the image datasets were calculated and compared using the McNemar test and receiver operating characteristics (ROC) analysis.

\section{Results}

\section{Radiation Dose}

The paired t test revealed that mean CTDIvol, DLP, and ED at the $80 \mathrm{kVp}$ setting $(0.13 \mathrm{mGy}, 3.30 \mathrm{mGy}-\mathrm{cm}$,
$0.050 \mathrm{mSv}$ ) were significantly lower than those at the 120 kVp setting (0.77 mGy, $19.02 \mathrm{mGy}-\mathrm{cm}, 0.285 \mathrm{mSv})(\mathrm{P}<$ 0.0001 ) (Table 1), resulting in a dose reduction of $82.5 \%$ at $80 \mathrm{kVp}$ compared to the $120 \mathrm{kVp}$ setting.

\section{Quantitative Image Analysis: Image Noise}

The results of quantitative analysis are summarized in Table 2. Among the four settings, mean image noise was highest at $80 \mathrm{kVp}$ with FBP reconstruction, followed by 80 kVp ASIR, $120 \mathrm{kVp} \mathrm{FBP}$, and $80 \mathrm{kVp}$ MBIR in descending order (mean \pm standard deviation; $60.36 \pm 8.01,47.02$ $\pm 6.33,23.48 \pm 1.92$, and $12.92 \pm 1.25$, respectively). With FBP reconstruction, the mean image noise of the 80 $k V p$ setting was significantly higher than that of the 120 $k V p$ setting (60.36 vs. $12.92 ; P<0.0001)$. In the $80 \mathrm{kVp}$ setting, image noise was significantly reduced by $22.1 \%$ (13.34/60.36) and 78.6\% (47.44/60.36) with ASIR and MBIR reconstruction, respectively $(P<0.0001)$, compared to that using standard FBP reconstruction. Representative images are presented in Figure 1.

\section{Qualitative Image Analysis}

In terms of image quality, both reviewers recorded their

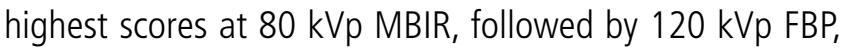
$80 \mathrm{kVp}$ ASIR and $80 \mathrm{kVp}$ FBP for all four characteristics (Table 2 and Fig. 2). There were significant differences in image quality scores among the four datasets in terms of the four characteristics $(P<0.0001)$. On post-hoc analysis, all comparisons of the image quality characteristics among the four datasets also showed statistical differences with $P$ values $<0.0001$ except for the comparisons between 120 kVp FBP and 80 kVp MBIR for bowel wall evaluation

Table 1. Radiation Dose at 80 and $120 \mathrm{kVp}$ CT for Evaluation of Inflammatory Bowel Disease in a Rabbit Model

\begin{tabular}{|c|c|c|c|}
\hline & $80 \mathrm{kVp}$ & $120 \mathrm{kVp}$ & Pvalue $^{\ddagger}$ \\
\hline $\begin{array}{l}\text { Volume CT Dose Index } \\
\text { (CTDI }_{\text {vol, }} \text { mGy) }\end{array}$ & 0.13 & 0.77 & \\
\hline $\begin{array}{l}\text { Dose Length Product } \\
(\mathrm{DLP}, \mathrm{mGy} \cdot \mathrm{cm})^{*}\end{array}$ & $3.30 \pm 0.58$ & $19.02 \pm 0.24$ & $<0.0001$ \\
\hline $\begin{array}{l}\text { Effective dose } \\
(E D, m S v)^{\star^{\dagger}}\end{array}$ & $0.050 \pm 0.009$ & $0.285 \pm 0.004$ & $<0.0001$ \\
\hline
\end{tabular}




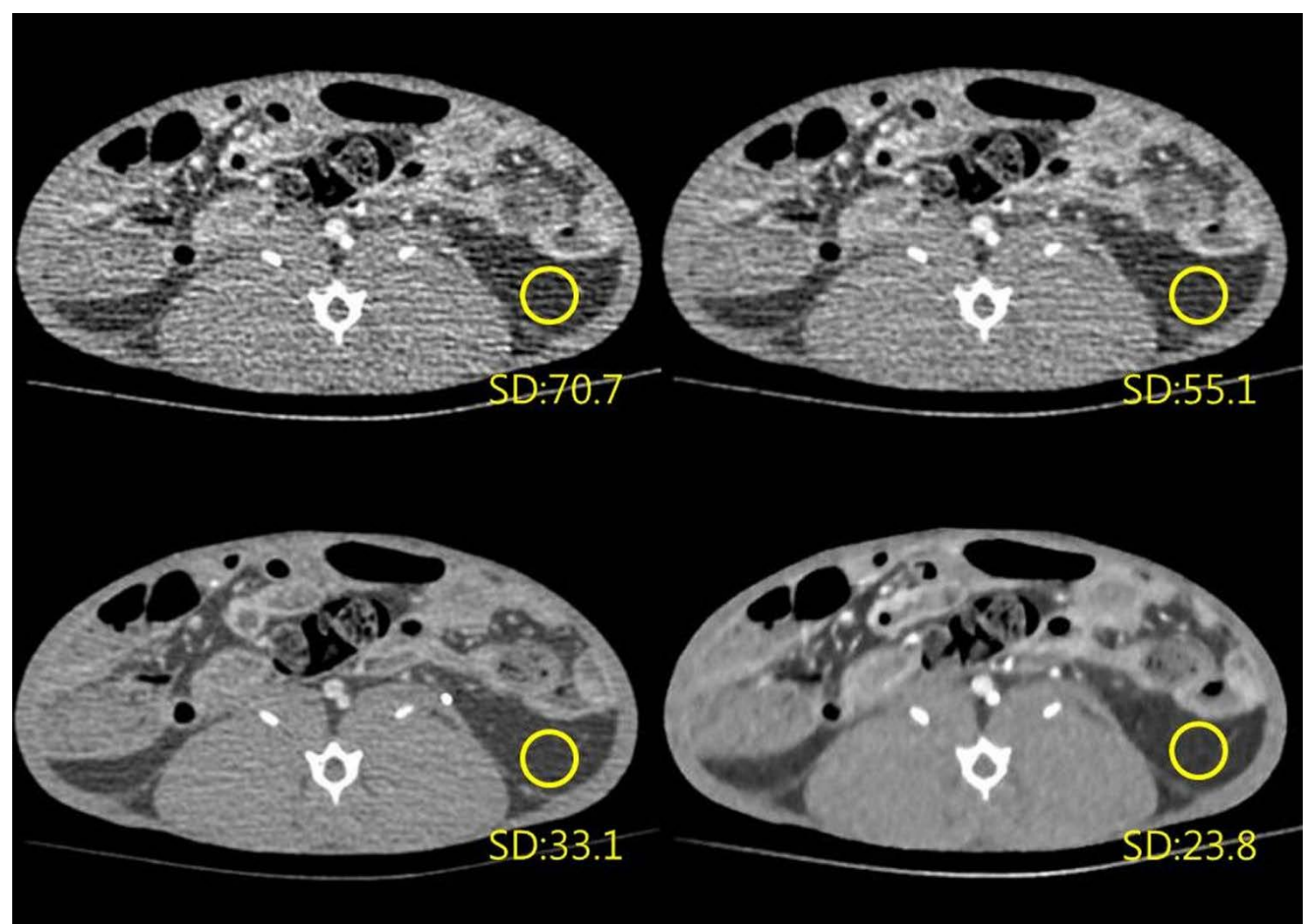

Fig. 1.80 and $120 \mathrm{kVpCT}$ images using various reconstruction algorithms. Image noise was the highest at $80 \mathrm{kVp}$ with FBP reconstruction (70.7, upper left), followed by 80 kVp 50\% ASIR (55.1, upper right), 120 kVp FBP (33.1, lower left), and 80 kVp MBIR (23.8, lower right).

Table 2. Image Noise and Image Quality Scores for Four Characteristics Assessed by Two Reviewers

\begin{tabular}{|c|c|c|c|c|c|}
\hline \multirow{2}{*}{ Category Evaluated by Reviewers } & \multicolumn{5}{|c|}{ Image Noise and Image Quality Score* (Mean \pm Standard Deviation) } \\
\hline & $80 \mathrm{kVp}$ FBP & $80 \mathrm{kVp} A S I R$ & $120 \mathrm{kVp} \mathrm{FBP}$ & $80 \mathrm{kVp} M \mathrm{MBIR}$ & Pvalue $^{\dagger}$ \\
\hline \multicolumn{6}{|l|}{ Image Noise } \\
\hline & $60.36 \pm 80.1$ & $47.02 \pm 6.33$ & $23.48 \pm 1.92$ & $12.92 \pm 1.25$ & $<0.0001$ \\
\hline \multicolumn{6}{|l|}{ Reviewer 1} \\
\hline Bowel wall & $1.43 \pm 0.50$ & $2.25 \pm 0.70$ & $4.21 \pm 0.50$ & $4.71 \pm 0.46$ & $<0.0001$ \\
\hline Mesenteric vessels & $1.96 \pm 0.79$ & $2.50 \pm 0.64$ & $3.93 \pm 0.38$ & $4.82 \pm 0.39$ & $<0.0001$ \\
\hline Liver & $1.64 \pm 0.62$ & $2.34 \pm 0.74$ & $3.96 \pm 0.19$ & $4.86 \pm 0.36$ & $<0.0001$ \\
\hline Overall image adequacy & $1.57 \pm 0.50$ & $2.43 \pm 0.63$ & $4.14 \pm 0.36$ & $4.79 \pm 0.42$ & $<0.0001$ \\
\hline \multicolumn{6}{|l|}{ Reviewer 2} \\
\hline Bowel wall & $1.29 \pm 0.46$ & $2.04 \pm 0.69$ & $4.21 \pm 0.50$ & $4.71 \pm 0.46$ & $<0.0001$ \\
\hline Mesenteric vessels & $1.71 \pm 0.71$ & $2.11 \pm 0.57$ & $4.11 \pm 0.32$ & $4.93 \pm 0.26$ & $<0.0001$ \\
\hline Liver & $1.71 \pm 0.60$ & $2.29 \pm 0.53$ & $3.93 \pm 0.26$ & $5.00 \pm 0.00$ & $<0.0001$ \\
\hline Overall image adequacy & $1.46 \pm 0.58$ & $2.25 \pm 0.65$ & $4.04 \pm 0.19$ & $4.93 \pm 0.26$ & $<0.0001$ \\
\hline
\end{tabular}

${ }^{*}$ Image scores range from 1 to 5: 1, poor; 2, acceptable; 3, good; 4, very good; 5, excellent. ${ }^{\dagger} P$ values were obtained using the repeated measure ANOVA. $\mathrm{FBP}=$ filtered back projection, $\mathrm{ASIR}=$ adaptive statistical iterative reconstruction, $\mathrm{MBIR}=$ model-based iterative reconstruction 


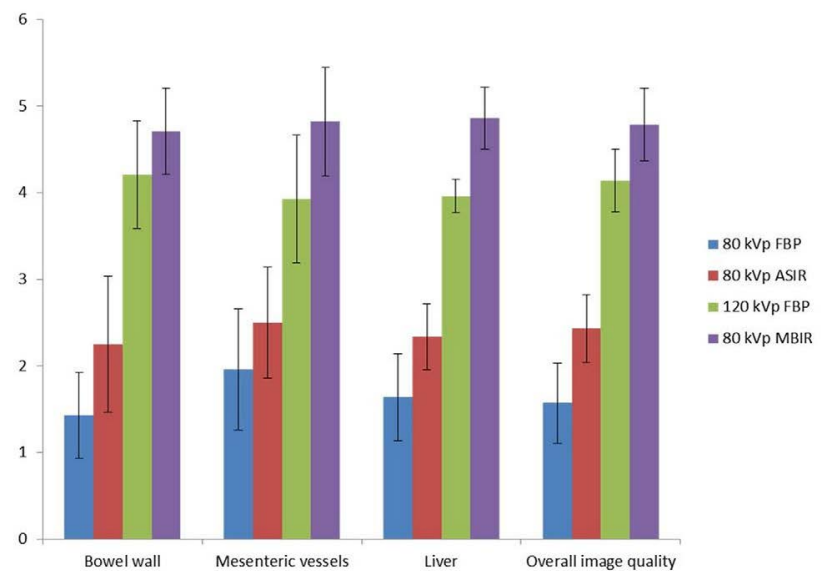

A

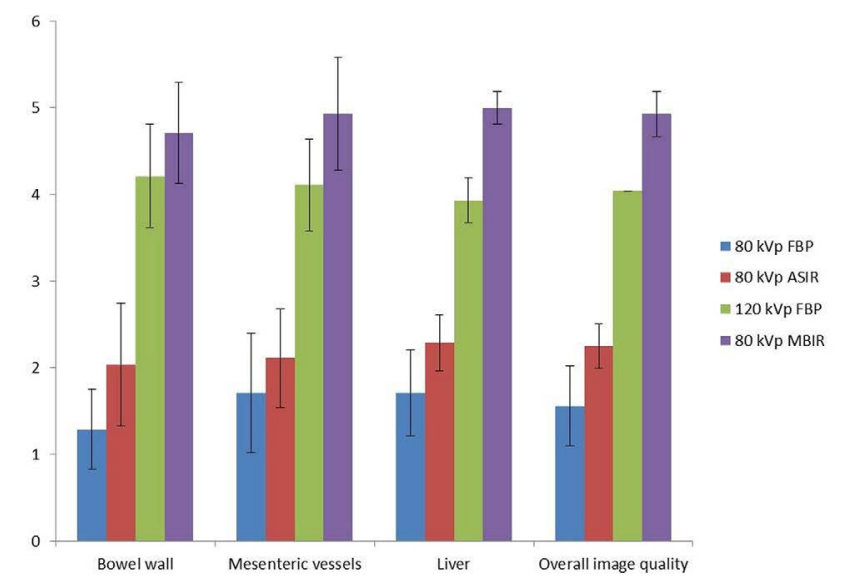

Fig. 2. Bar graphs showing the mean and standard deviation of image quality for the four image quality characteristics by the two reviewers. A. Results of reviewer 1. B. Results of reviewer 2. Regardless of the reviewers or image characteristics, the mean image quality was lowest at 80 kVp FBP, significantly improved with statistic-based IR (ASIR), and further improved with full knowledge-based IR (MBIR) $(\mathrm{P}<0.0001)$.

Table 3. Diagnostic Performance for the Differentiation between Normal Bowels and Inflammatory Bowel Disease

\begin{tabular}{llcccc}
\hline & Reviewers & $80 \mathrm{kVp} \mathrm{FBP}$ & $80 \mathrm{kVp}$ ASIR & $120 \mathrm{kVp} \mathrm{FBP}$ & $80 \mathrm{kVp} \mathrm{MBIR}$ \\
\hline Area under the curve & Reviewer 1 & 0.883 & 0.992 & 1 & 1 \\
& Reviewer 2 & 0.967 & 0.997 & 1 & 1 \\
Sensitivity & Reviewer 1 $^{\dagger}$ & $61.1 \%$ & $83.3 \%$ & $100 \%$ & $100 \%$ \\
\multirow{3}{*}{ Specificity } & Reviewer 2 & $83.3 \%$ & $94.4 \%$ & $100 \%$ & $100 \%$ \\
& Reviewer 1 & $100 \%$ & $100 \%$ & $100 \%$ & $100 \%$ \\
& Reviewer 2 & $100 \%$ & $100 \%$ & $100 \%$ & $100 \%$ \\
\hline
\end{tabular}

${ }^{*}$ Significant differences were found in the area under the curve between $80 \mathrm{kVp}$ FBP and the other three settings by reviewer $1 .{ }^{\dagger}$ Sensitivity at the $80 \mathrm{kVp}$ FBP setting was significantly lower than those at the $120 \mathrm{kVp} \mathrm{FBP}$ and $80 \mathrm{kVp}$ MBIR settings. FBP=filtered back projection, ASIR=adaptive statistical iterative reconstruction, MBIR=model-based iterative reconstruction

by both reviewers $(P=0.019$ for reviewer $1, P=0.028$ for reviewer 2) and between $80 \mathrm{kVp}$ FBP and $80 \mathrm{kVp}$ ASIR for mesenteric vessel evaluation by reviewer $2(P=0.002)$.

\section{Diagnostic Performance}

Table 3 and Figure 3 demonstrate the individual performances of the two radiologists for the differentiation between normal bowels and IBD. Areas under the curve were highest at $120 \mathrm{kVp}$ FBP (1 for both reviewers) and $80 \mathrm{kVp}$ MBIR settings (1 for both reviewers), followed by $80 \mathrm{kVp}$ ASIR (0.992 and 0.997 for readers 1 and 2, respectively) and the $80 \mathrm{kVp}$ FBP settings (0.883 and 0.967). The difference between $80 \mathrm{kVp}$ FBP and the other three settings was statistically significant for reviewer 1 $(P=0.0143 \sim 0.0163)$. Sensitivity for differentiation was also highest at $120 \mathrm{kVp}$ FBP (100\% for both reviewers) and $80 \mathrm{kVp}$ MBIR settings (100\% for both reviewers), followed by $80 \mathrm{kVp}$ ASIR ( $83.3 \%$ and $94.4 \%$ ) and 80 kVp FBP settings (61.1\% and $83.3 \%$ ). The difference was statistically significant between $80 \mathrm{kVp}$ FBP and 120 kVp FBP and between 80 kVp FBP and 80 kVp MBIR for reviewer $1(P=0.0156)$. Specificity was $100 \%$ in all four settings for both reviewers. Representative images are presented in Figure 4.

\section{Discussion}

In our study, we found that ultra-low dose $80 \mathrm{kVp} / 5$ mAs CT was not feasible using the standard FBP algorithm owing to severe image noise, poor image quality, and low diagnostic performance. The AUC (0.883) and sensitivity $(61.1 \%)$ of $80 \mathrm{kVp}$ images reconstructed with 


\section{KJAR}

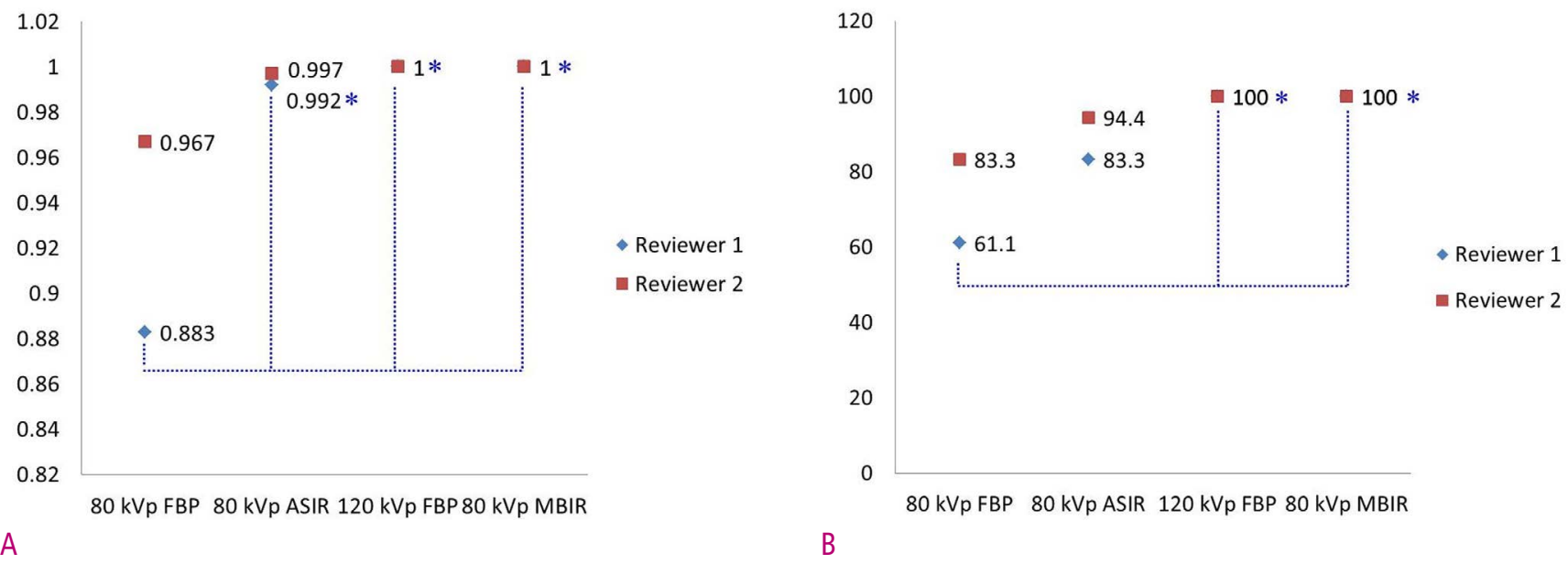

Fig. 3. Dot graphs showing the diagnostic performance in differentiating normal bowels from inflammatory bowel disease in 28 rabbits.

A. Areas under the curve (AUCs) of the two reviewers: The AUC (0.883 and 0.967) of $80 \mathrm{kVp}$ CT reconstructed with the FBP algorithm was the lowest. However, with the application of statistic-based IR (ASIR) and full IR (MBIR) algorithms, AUC on $80 \mathrm{kVp}$ CT improved to 0.992 1, which was not significantly different from that (1) found at the conventional $120 \mathrm{kVp}$ FBP setting. The difference was significant in reviewer 1. B. Sensitivity of the two reviewers: Sensitivity (61.1\% and $83.3 \%)$ of $80 \mathrm{kVp} \mathrm{CT}$ reconstructed with the FBP algorithm was the lowest. However, with the application of statistic-based IR (ASIR) and full IR (MBIR) algorithms, sensitivity on $80 \mathrm{kVp} \mathrm{CT}$ improved to $83.3 \%$ 100\%, respectively, which was not significantly different from that (100\%) found at the conventional $120 \mathrm{kVp}$ FBP setting. The difference was significant in reviewer 1. Significant differences between the settings are shown with dotted lines and *.

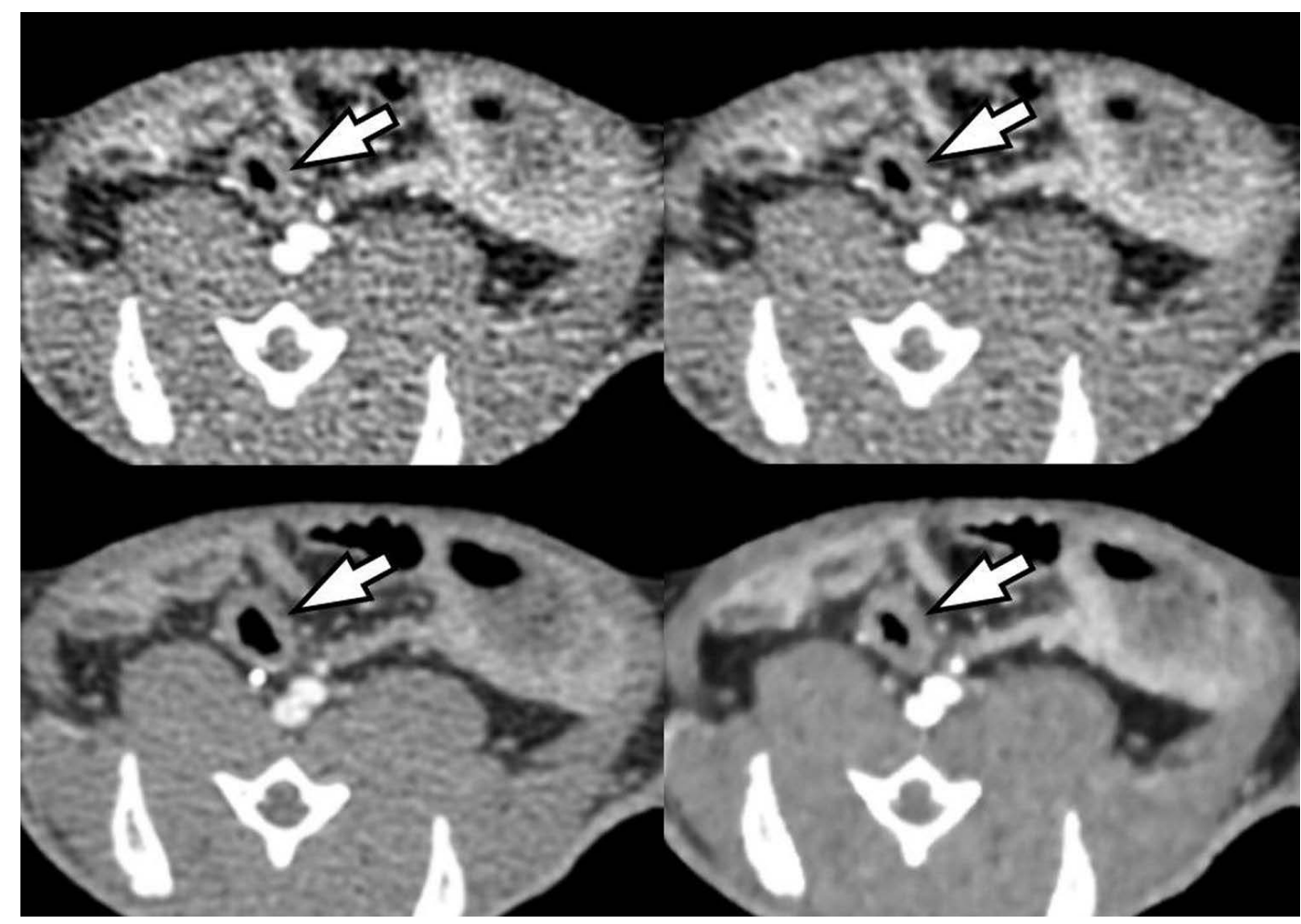

Fig. 4. CT image of acute colitis in a rabbit model. Image noise was the highest at $80 \mathrm{kVp} C T$ with FBP reconstruction (upper left), followed by $80 \mathrm{kVp} \mathrm{50 \%} \mathrm{ASIR} \mathrm{(upper} \mathrm{right),} 120 \mathrm{kVp} \mathrm{FBP} \mathrm{(lower} \mathrm{left),} \mathrm{and} 80 \mathrm{kVp} \mathrm{MBIR} \mathrm{(lower} \mathrm{right).} \mathrm{Due} \mathrm{to} \mathrm{severe} \mathrm{image} \mathrm{noise,} \mathrm{the} \mathrm{two} \mathrm{reviewers}$ misinterpreted the thickened inflamed bowel (arrows) as a normal bowel at the $80 \mathrm{kVp}$ FBP setting (upper left). With the other three settings, the two reviewers correctly diagnosed the inflammatory bowel disease. 
the FBP algorithm provided the lowest values and was not deemed acceptable for one reviewer (reviewer 1). However, with the application of hybrid IR (ASIR) and full IR (MBIR) algorithms, the AUC and sensitivity of $80 \mathrm{kVp}$ CT improved to 0.992 1 and 83.3\% 100\%, respectively, which was not significantly different from those found at the conventional $120 \mathrm{kVp}$ FBP setting (1 and 100\%). Our observation is of practical importance because we demonstrated that $80 \mathrm{kVp} \mathrm{CT}$ using IR algorithms may decrease the risk of radiation exposure while maintaining the quality of diagnostic information, especially in young IBD patients subject to repeated CT examinations. Indeed, the mean effective radiation dose of $80 \mathrm{kVp} \mathrm{CT}$ was only $0.05 \mathrm{mSv}$ which is significantly lower than that ( $0.285 \mathrm{mSv}$ ) of conventional $120 \mathrm{kVp} \mathrm{CT}$. Thus, with the application of IR algorithms, we can markedly reduce radiation dose by $82.5 \%$ while maintaining diagnostic performance. Although the results of this animal study cannot be directly applicable to those of a human study, our results suggest that low kVp CT at $80 \mathrm{kVp}$ and $5 \mathrm{mAs}$ may be feasible with the aid of IR algorithms on CT.

The superior performance of $I R$ algorithms in comparison with FBP reconstruction can be explained by its effectiveness in noise reduction and prevention of artifacts related to the low tube potential. Indeed, we observed a completely opposite trend between image noise and image quality for all four characteristics in both reviewers. The highest image noise was measured at 80 kVp FBP (60.36), followed by 80 kVp ASIR (47.02), 120 kVp FBP (23.48), and $80 \mathrm{kVp}$ MBIR (12.92), in descending order. Accordingly, the lowest image quality score was achieved at $80 \mathrm{kVp}$ FBP (1.29 1.96), followed by $80 \mathrm{kVp}$ ASIR (2.04 2.50), 120 kVp FBP (3.93 4.21), and 80 kVp MBIR (4.71 5). A similar trend was also observed between image noise and diagnostic performance. The lowest sensitivity and AUC was achieved at $80 \mathrm{kVp}$ FBP (61.1\% and $83.3 \% ; 0.883$ and 0.967 , for readers 1 and 2 , respectively), followed by $80 \mathrm{kVp}$ ASIR (83.3\% and $94.4 \%$; 0.992 and 0.997), $120 \mathrm{kVp}$ FBP (100\%; 1), and $80 \mathrm{kVp}$ MBIR (100\%; 1). From these observations, we can deduce that the reduction in image noise may directly reflect the improvement in image quality measured by qualitative scoring as well as by sensitivity and AUC.

In addition to the reduction in image noise, the higher attenuation of iodine at $80 \mathrm{kVp}$ than at $120 \mathrm{kVp}$ may also have been responsible for the highest image quality of $80 \mathrm{kVp}$ MBIR. Reducing the tube voltage from 120 to 80 $k V p$ has the advantage of increasing iodine attenuation by a factor of 1.7 as the k-edge of iodine is closer to the reduced tube voltage $(4,5)$. This increased attenuation of iodine, in turn, can lead to the increased contrast of vascular structures such as mesenteric vessels and enhanced organs such as the bowel wall and liver. In addition, the increased image contrast obtained at the low $k V p$ setting can be beneficial in evaluating subjects with suspected IBD as changes in the active disease, such as mucosal enhancement and mesenteric hypervascularity, would be readily apparent if the image noise is adequately suppressed (8). Thus, the high image quality and diagnostic performance observed at the $80 \mathrm{kVp}$ MBIR setting in our study may be due to both increased image contrast as well as more effective noise reduction.

In our study, we used both hybrid, statistic-based IR (ASIR) and full knowledge-based IR (MBIR) algorithms to help compensate for the increased image noise in $80 \mathrm{kVp}$ scanning. Although the hybrid IR technique was also able to significantly reduce the image noise on $\mathrm{CT}$ compared with FBP reconstruction, a certain amount of image noise and artifacts remained. Such remnant image noise may have been responsible for the intermediate image quality observed with the $80 \mathrm{kVp}$ ASIR setting. On the other hand, full IR was observed to further decrease image noise, generating virtually noise-free images. Knowledgebased full IR is a new algorithm, which unlike previous IR algorithms, does not involve blending with FBP images, and although it may be mathematically more complex, it is also more accurate (9-11). The knowledge-based approach accurately determines data, image statistics, and system models, which depict the geometry and physical characteristics of the CT scanner. Owing to its computational complexity, the full IR algorithm requires somewhat longer reconstruction times (9-11), however, with continued rapid improvement in computer hardware, a reduction in reconstruction times can be expected. With the superior results demonstrated with MBIR in this study as well as in previous studies (9-11), removing this limitation of reconstruction time may eventually enable the replacement of ASIR with knowledge-based IR in the near future.

Our study has several limitations. First, while the TNBSA- 
induced IBD model is advantageous in terms of its high success rate, it does not fully reflect all disease states from acute to chronic in patients with IBD. However, as we had initially planned to establish an acute IBD model, establishing the full disease spectrum was beyond the scope of our current study. In addition, although our purpose was to examine IBD, inflammation is limited to the colon and does not model small bowel involvement. However, since the mechanism of acute inflammation is mediated through the same cascade in different organs, we can expect similar results for small bowel inflammation imaging. Second, an animal study cannot truly represent a human study with different body sizes and body compositions. Considering that radiation dose is highly dependent on body habitus, our study results cannot be directly applicable to human subjects. Third, we only analyzed CT images obtained from a singlevendor CT scanner whose IR algorithms may not be the same as those of other CT scanners available from different vendors. According to a recent article by Löve et al. (12), although most IR algorithms have been shown to improve image quality and reduce image noise, different IR algorithms by different CT vendors have their own strengths and weaknesses. Therefore, our results may not be directly applicable to other IR algorithms of different CT scanners.

In conclusion, ultra-low dose $80 \mathrm{kVp} \mathrm{CT}$ is not feasible using the standard FBP algorithm. However, with the application of IR algorithms, the diagnostic performance of $80 \mathrm{kVp}$ CT was acceptable in a rabbit IBD model and on par with that reconstructed with conventional $120 \mathrm{kVp}$ FBP.

ORCID: Cheong-II Shin: https://orcid.org/0000-0002-5457-4523; Se Hyung Kim: https://orcid.org/0000-0001-8664-0356; Mi Hye Yu: https://orcid.org/00000003-0519-7853; ljin Joo: https://orcid.org/0000-0002-1341-4072; Joon Koo Han: https://orcid.org/0000-0001-5916-5545

\section{Acknowledgments}

This study was supported by the Basic Science Research Program through the National Research Foundation of Korea (NRF) funded by the Ministry of Science, ICT \& Future Planning (NRF-2021R1F1A1046393)

\section{References}

1. Paulsen SR, Huprich JE, Fletcher JG, Booya F, Young $B M$, Fidler JL, et al. CT enterography as a diagnostic tool in evaluating small bowel disorders: review of clinical experience with over 700 cases. Radiographics 2006;26:641-57.

2. Hara AK, Swartz PG. CT enterography of Crohn's disease. Abdom Imaging 2009;34:289-95.

3. Brenner DJ. Should computed tomography be the modality of choice for imaging Crohn's disease in children? The radiation risk perspective. Gut 2008;57:1489-90.

4. Reid J, Gamberoni J, Dong F, Davros W. Optimization of kVp and $\mathrm{mAs}$ for pediatric low-dose simulated abdominal CT: is it best to base parameter selection on object circumference? AJR Am J Roentgenol 2010;195:1015-20.

5. Kalva SP, Sahani DV, Hahn PF, Saini S. Using the K-edge to improve contrast conspicuity and to lower radiation dose with a 16-MDCT: a phantom and human study. J Comput Assist Tomogr 2006;30:391-7.

6. Nakayama Y, Awai K, Funama Y, Hatemura M, Imuta M, Nakaura $T$, et al. Abdominal CT with low tube voltage: preliminary observations about radiation dose, contrast enhancement, image quality, and noise. Radiology 2005;237:945-51.

7. Hur S, Lee JM, Kim SJ, Park JH, Han JK, Choi BI. 80-kVp CT using Iterative Reconstruction in Image Space algorithm for the detection of hypervascular hepatocellular carcinoma: phantom and initial clinical experience. Korean J Radiol 2012;13:152-64.

8. Kaza RK, Platt JF, Al-Hawary MM, Wasnik A, Liu PS, Pandya A. CT enterography at $80 \mathrm{kVp}$ with adaptive statistical iterative reconstruction versus at $120 \mathrm{kVp}$ with standard reconstruction: image quality, diagnostic adequacy, and dose reduction. AJR Am J Roentgenol 2012;198:1084-92.

9. Pickhardt PJ, Lubner MG, Kim DH, Tang J, Ruma JA, del Rio $A M$, et al. Abdominal CT with model-based iterative reconstruction (MBIR): initial results of a prospective trial comparing ultralow-dose with standard-dose imaging. AJR Am J Roentgenol 2012;199:1266-74.

10. Yoon MA, Kim SH, Lee JM, Woo HS, Lee ES, Ahn SJ, et al. Adaptive statistical iterative reconstruction and Veo: assessment of image quality and diagnostic performance in CT colonography at various radiation doses. J Comput Assist 
Tomogr 2012;36:596-601.

11. Lee ES, Kim SH, Im JP, Kim SG, Shin $\mathrm{Cl}$, Han JK, et al. Effect of different reconstruction algorithms on computeraided diagnosis (CAD) performance in ultra-low dose CT colonography. Eur J Radiol 2015;84:547-54.

12. Löve $A$, Olsson ML, Siemund R, Stålhammar F, BjörkmanBurtscher IM, Söderberg M. Six iterative reconstruction algorithms in brain CT: a phantom study on image quality at different radiation dose levels. $\mathrm{Br} J$ Radiol 2013;86:20130388.

13. Shin $\mathrm{Cl}$, Kim SH, Lee ES, Lee DH, Hwang EJ, Chung SY, et al. Ultra-low peak voltage CT colonography: effect of iterative reconstruction algorithms on performance of radiologists who use anthropomorphic colonic phantoms. Radiology 2014;273:759-71.

14. Kim M, Lee JM, Yoon JH, Son H, Choi JW, Han JK, et al. Adaptive iterative dose reduction algorithm in CT: effect on image quality compared with filtered back projection in body phantoms of different sizes. Korean J Radiol 2014;15:195204.

15. ICRP. 1990 Recommendations of the International Commission on Radiological Protection. ICRP Publication 60. Ann ICRP 1991;21.

\title{
초저선량 CT를 이용한 염증성 장질환 평가에서 서로 다른 반복재구성 기법의 효과: 토끼 모델을 이용한 실험적 연구
}

\author{
신청일1,2, 김세형1,2,4, 유미혜 ${ }^{3}$, 주이진 ${ }^{1,2}$, 한준구 ${ }^{1,2,4}$ \\ '서울대학교병원 영상의학과 \\ ${ }^{2}$ 서울대학교 의과대학 영상의학교실 \\ 3건국대학교병원 영상의학과 \\ ${ }^{4}$ 서울대학교 의학연구원 방사선의학연구소
}

목 적: 토끼 염증성 장질환 모델에서 초저선량 CT가 적합한지를 평가하고, 두 개의 다른 반복재구성 알고리즘의 효 과를 규명하고자 한다.

방 법: 28마리의 토끼를 염증성 장질환 군 (18 마리)과 대조군 (10 마리) 두 그룹으로 무작위로 나눈다. 염증성 장질 환 모델을 구축하기 위해 $5 \%$ tri-nitrobenzene sulfonic acid 용액 $3 \mathrm{ml}$ 를 토끼의 S자 결장에 삽입한다. $80 \mathrm{kVp}$ 와 $120 \mathrm{kVp}$ 를 이용하여 CT를 촬영하고, $80 \mathrm{kVp} \mathrm{CT}$ 는 여과중첩재구성법, 하이브리드 반복재구성기법, 및 완전 반복재 구성기법을 이용하여 재구성하고, $120 \mathrm{kVp} \mathrm{CT}$ 영상은 여과중첩재구성법을 이용하여 재구성한다. 유효방사선량, 영 상잡음, 영상의 질, 및 두 영상의학과 의사의 진단능을 비교한다.

결 과: $80 \mathrm{kVp} \mathrm{CT}$ 의 평균 유효방사선량은 $0.05 \mathrm{mSv}$ 로 $120 \mathrm{kVp} \mathrm{CT}$ 의 평균 유효방사선량 $0.285 \mathrm{mSv}$ 에 비해 유 의하게 낮았다. 여과중첩재구성법 $80 \mathrm{kVp} \mathrm{CT}$ 의 평균 영상 잡음 (60.36)은 두 반복재구성기법 (하이브리드 반복재 구성기법: 47.02, 완전 반복재구성기법: 12.92)에 비해 유의하게 높았다 ( $\mathrm{P}<0.0001)$. 평균 영상의 질은 여과중첩재구 성법 $80 \mathrm{kVp}$ CT에서 가장 낮았고, 두 반복재구성기법을 적용했을 때 유의하게 향상되었다 $(\mathrm{P}<0.0001)$. 정상 소장 과 염증성 장질환이 이환된 소장을 감별하는 민감도와 수신자 조작 특성 곡선하 면적값은 여과중첩재구성법 $80 \mathrm{kVp}$ CT 영상에서 가장 낮았고 $(61.1 \%, 83.3 \% ; 0.883,0.967)$, 두 반복재구성기법을 적용했을 때 유의하게 향상되었으며 (83.3\% 100\%; 0.992 1) (P<0.0001), 여과중첩재구성법 $120 \mathrm{kVp} \mathrm{CT}$ 값과 비슷한 수준이었다 (100\% and 1).

결 론: 염증성 장질환 토끼 모델에서 초저선량 $80 \mathrm{kVp} \mathrm{CT}$ 는 적합하지 않았다. 그러나, 반복재구성기법을 이용하여 재구성한 경우, 초저선량 $80 \mathrm{kVp} \mathrm{CT}$ 영상의 진단능은 여과중첩재구성법 $120 \mathrm{kVp} \mathrm{CT}$ 영상과 비슷하며 만족할 만한 수준이었다. 